Pages 195-199 in A Future Beyond Growth: Towards a Steady State Economy, eds. Haydn Washington and Paul Twomey. London: Routledge, Earthscan, 2016

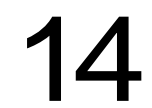

\title{
SUSTAINABLE DEVELOPMENT VS. SUSTAINABLE BIOSPHERE
}

\author{
Holmes Rolston III \\ COLORADO STATE UNIVERSITY
}

\begin{abstract}
In sustainability debates, there are two poles, complements yet opposites. Economy can be prioritized, with the environment contributory to economics at the center. This is sustainable development, an approach widely advocated by the United Nations. At the other pole, a sustainable biosphere model demands a baseline quality of environment. The economy must be worked out within such quality of life in a quality environment. This is advocated by the Ecological Society of America. People and their Earth have entwined destinies; that past truth continues in the present and will remain a pivotal concern in the new millennium. What we most ought to develop and sustain is a sense of respect for this wonderland planet.
\end{abstract}

The United Nations Conference on Environment and Development entwined its twin concerns into 'sustainable development'. No one wants unsustainable development, and sustainable development has for the two decades since Rio remained the favored model. The duty seems unanimous, plain, and urgent. Only so can this good life continue. Over 150 nations have endorsed sustainable development. The World Business Council on Sustainable Development includes 130 of the world's largest corporations.

Proponents argue that sustainable development is useful because it is a wideangle lens. The specifics of development are unspecified, giving peoples and nations the freedom and responsibility of self-development. This is an orienting concept that is at once directed and encompassing, a coalition-level policy that sets aspirations, thresholds, and allows pluralist strategies for their accomplishment.

Critics reply that sustainable development is just as likely to prove an umbrella concept that requires little but superficial agreement, bringing a constant illusion of consensus, glossing over deeper problems with a rhetorically engaging word. Seen at more depth, there are two poles, complements yet opposites. Economy can be 


\section{Holmes Rolston III}

prioritized, the usual case, and anything can be done to the environment, so long as the continuing development of the economy is not jeopardized thereby. The environment is kept in orbit with economics at the center.

Develop! Develop! Develop! One ought to develop (since that increases social welfare and the abundant life), and the environment will constrain that development if and only if a degrading environment might undermine ongoing development. The underlying conviction is that the trajectory of the industrial, technological, commercial world is generally right - only the developers in their enthusiasm have hitherto failed to recognize environmental constraints.

If economics is the driver, we will seek maximum harvests, using pesticides and herbicides on land, a bioindustrial model, pushing for bigger and more efficient agriculture, as long as this is sustainable. This will push to the limits the environmental constraints of dangerous pesticide and herbicide levels on land and in water, surface and ground water, favoring monocultures, typically of annuals, inviting soil erosion and invasive species. The model is extractive, commodification of the land. Land and resources are 'natural capital'.

At the other pole, the environment is prioritized. A 'sustainable biosphere' model demands a baseline quality of environment. The economy must be worked out within such a policy for environmental quality objectives (clean air, water, stable agricultural soils, attractive residential landscapes, forests, mountains, rivers, rural lands, parks, wildlands, wildlife, renewable resources). Winds blow, rains fall, rivers flow, the sun shines, photosynthesis takes place, carbon recycles all over the landscape. These processes have to be sustained. The economy must be kept within an environmental orbit. One ought to conserve nature, the ground-matrix of life. Development is desired, but even more, society must learn to live within the carrying capacity of its landscapes. The model is land as community.

Sustainable. Sustainable, but sustainable what? 'Sustainable' is an economic but also an environmental term. The Ecological Society of America advocates research and policy that will result in a sustainable biosphere. 'Achieving a sustainable biosphere is the single most important task facing humankind today' (Risser et al. 1991). The fundamental flaw in 'sustainable development' is that it sees the Earth as resource, as commodity only. The underlying conviction in the sustainable biosphere model is that the current trajectory of the industrial, technological, commercial world is generally wrong, because it will inevitably overshoot. The environment is not some undesirable, unavoidable set of constraints. Rather, nature is the matrix of multiple values; many, even most of them, are not counted in economic transactions. In a more inclusive accounting of what we wish to sustain, nature provides numerous other values (aesthetic experiences, biodiversity, sense of place and perspective), and these are getting left out. The Millennium Ecosystem Assessment explores this in great detail. Though it is an anthropocentric document, it does insist that we depend heavily on ecosystem services.

A central problem with contemporary global development is that the rich grow richer and the poor poorer. Many fear that this is neither ethical nor sustainable. The rich and powerful are always ready to exploit both nature and people. This 
forces the poor as well as the rich to over-exploit nature, and brings escalating environmental degradation, more tragedy of the commons, with instability and collapse. Such issues come under another inclusive term, 'environmental justice'.

For thousands of years of human history, we have been pushing back limits. Especially in the West, we have lived with a deep-seated belief that life will get better, that one should hope for abundance, and work toward obtaining it. Develop! Develop! Develop! Economists call such behavior 'rational'; humans will maximize their capacity to exploit their resources. Moral persons will also maximize human satisfactions, at least those that support the good life, which does not just include food, clothing, and shelter, but an abundance, more and more goods and services that people want. Such growth is always desirable. We have built development into our concept of human rights: a right to self-development, to self-realization. Such an egalitarian ethic scales everybody up and drives an unsustainable world. When everybody seeks their own good, there is escalating consumption. But equally, if one seeks justice and charity, when everybody seeks everybody else's good, there is, again, escalating consumption. But this continually pushes the system toward its limits.

Many will say, if you wish to know what policy to sustain, you should ask an ecologist. Ecology is strikingly like medical science. Both are therapeutic sciences. Ecologists are responsible for environmental health, which is really another form of public health. Health is not just skin-in; it is skin-out too. One cannot be healthy in a sick environment. Health is something that is easy to advocate and the criteria seem to be scientific. That helps move us toward sustainable development.

But ecologists have no special competence in evaluating whether to give priority to economic development or to conserving nature beyond what ecology is required for human development. A people on a landscape will have to make value judgments about how much original nature they have, or want, or wish to restore, and how much culturally modified nature they want, and whether it should be culturally modified this way or that. Ecologists may be able to tell us what our options are, what will work and what will not, what is the minimum baseline health of landscapes. But there is nothing in ecology per se that gives ecologists any authority or skills at making these further social decisions, whether to feed more people or save the tigers. Science does not enable us to choose between diverse options, all of which are scientifically possible.

I can equally substitute the word 'economics' for 'science'. Economists have no special competence in evaluating what rebuilding of nature a culture desires, or how far the integrity of wild nature should be sacrificed to achieve this. Economists, like the ecologists, may be able to tell us what our options are, what will work and what will not. But there is nothing in economics per se that gives economists any authority or skills at making these further social decisions. What the sciences may teach us is how to get more $x$ out of $y$, but they do not teach whether we ought to. After four centuries during which science and economics have progressively illuminated us about how we can transform nature into the goods we want, the value questions raised in economics, too, are as sharp and as painful as ever. 


\section{Holmes Rolston III}

Humans are not well equipped to deal with the sorts of global level problems we now face. The classical institutions - family, village, tribe, nation, agriculture, industry, law, medicine, even school and church - have shorter horizons. We are genetically driven to care for children, grandchildren. Far-off descendants and distant races do not have much biological hold on us. Across the era of human evolution, little in our behavior affected those remote from us in time or in space, and natural selection shaped only our conduct toward those closer. Further, we have also made such conduct moral. Care for your children; help your neighbors. So we have a biological legacy coupled with a moral legacy that endorses continuing development on our local and national landscapes. Global threats require us to act in massive concert of which we are incapable. If so, humans may bear within themselves the seeds of their own destruction. More bluntly, more scientifically put: our genes, once enabling our adaptive fit, will in the next millennium prove mal-adaptive and destroy us.

Is there any hope? There are some good signs. Humans can sometimes get larger frames of reference. The European Union has transcended national interests with surprising consensus about environmental issues. Kofi Annan, Secretary General of the United Nations, praised the Montreal Protocol, with its five revisions, widely adopted (191 nations) and implemented as the most successful international agreement yet. All the developed nations, except the United States and Australia, have signed the Kyoto Protocol. The Convention on International Trade in Endangered Species of Wild Fauna and Flora (CITES) has been signed by 112 nations. There are over 150 international agreements (conventions, treaties, protocols, etc.), registered with the United Nations, that deal directly with environmental problems (United Nations Environment Programme 1997; Rummel-Bulska and Osafo 1991). So there is some evidence that we can make these larger collective visions work.

One of the concerns of the Millennium Ecosystem is that we do not have any theoretical basis to alert us to impending dangers, especially as it affects the poor. There are many thresholds, trigger points, uncertainties. If you are always pushing a system toward its limits, and you do not know the danger zones, then you are likely to crash. We need to think of ourselves more globally.

People and their Earth have entwined destinies; that past truth continues in the present, and will remain a pivotal concern in the new millennium. Humans can move past thinking of themselves as local citizens, even as national citizens, and reach this more inclusive sense of worldwide entanglements. To get there from here, start by thinking how the air does move around the globe, that the climate is a set of complex interconnections. That will lead us to connecting sustainable development with a sustainable biosphere. We are moving in the direction of thinking of ourselves as residents on Earth, of the biosphere as a living community of life.

Sustainable development is impossible without a sustainable biosphere. The fundamental flaw in sustainable development, we earlier said, was in seeing Earth as resource only. Now we further see that first priority flaw as moral. Ecologists, 
economists - and ethicists and theologians - alike need to learn this: There is something morally naive about living in a reference frame where one species takes itself as absolute and values everything else as a resource to be developed, even if we phrase it that we are taking ourselves as primary and everything else as secondary. The vision we need even beyond a sustainable biosphere is respect for life, even reverence for life.

Develop! Develop! Maximize development! Is that the future of life on Earth? Maybe what you want to develop and sustain is a sense of respect for this wonderland planet.

(The editors would like to thank Jack Lee and Ria University Press for permission to publish this paper, originally from Lee, J. (ed.) (2010) Sustainability and Quality of Life, Palo Alto CA: Ria University Press, ISBN: 978-0-97434724-9).

\section{References}

Risser, P. G., Lubchenco, J., and Levin, S. (1991) 'Biological Research Priorities - A Sustainable Biosphere', Bioscience, vol 47, pp. 625-627.

Rummel-Bulska, I. and Osafo, S. (eds.) (1991) Selected Multilateral Treaties in the Field of the Environment, II, Cambridge: Grotius Publications.

United Nations Environment Programme (1997) Register of International Treaties and Other Agreements in the Field of the Environment, Nairobi: United Nations Environment Programme. 